\title{
The biomechanical response of persons with transfemoral amputation to variations in prosthetic knee alignment during level walking
}

\author{
Sara R. Koehler-McNicholas, PhD; ${ }^{1-3^{*}}$ Robert D. Lipschutz, CP, ${ }^{1,4}$ Steven A. Gard, PhD ${ }^{1-3}$ \\ ${ }^{1}$ Northwestern University Prosthetics-Orthotics Center, Department of Physical Medicine and Rehabilitation, Fein- \\ berg School of Medicine, Northwestern University, Chicago, IL; ${ }^{2}$ Department of Biomedical Engineering, McCormick \\ School of Engineering and Applied Science, Northwestern University, Evanston, IL; ${ }^{3}$ Jesse Brown VA Medical Center, \\ Chicago, IL; ${ }^{4}$ Rehabilitation Institute of Chicago, Chicago, IL
}

\begin{abstract}
Prosthetic alignment is an important factor in the overall fit and performance of a lower-limb prosthesis. However, the association between prosthetic alignment and control strategies used by persons with transfemoral amputation to coordinate the movement of a passive prosthetic knee is poorly understood. This study investigated the biomechanical response of persons with transfemoral amputation to systematic perturbations in knee joint alignment during a level walking task. Quantitative gait data were collected for three alignment conditions: bench alignment, $2 \mathrm{~cm}$ anterior knee translation (ANT), and $2 \mathrm{~cm}$ posterior knee translation (POST). In response to a destabilizing alignment perturbation (i.e., the ANT condition), participants significantly increased their early-stance hip extension moment, confirming that persons with transfemoral amputation rely on a hip extensor strategy to maintain knee joint stability. However, participants also decreased the rate at which they loaded their prosthesis, decreased their affected-side step length, increased their trunk flexion, and maintained their prosthesis in a more vertical posture at the time of opposite toe off. Collectively, these results suggest that persons with transfemoral amputation rely on a combination of strategies to coordinate stance-phase knee flexion. Further, comparatively few significant changes were observed in response to the POST condition, suggesting that a bias toward posterior alignment may have fewer implications in terms of stance-phase, knee joint control.
\end{abstract}

Key words: alignment, amputation, artificial limbs, gait analysis, hip, knee, load cell, transfemoral, treadmill, trunk.

\section{INTRODUCTION}

Transfemoral amputation is a life-altering event that currently affects approximately 550,000 people living in the United States [1-2]. By the year 2050, this number is expected to more than double, as amputations secondary to diabetes mellitus and dysvascular conditions become increasingly common [2]. To address the needs of this growing population, it is imperative that long-term, remedial use of transfemoral prostheses restore mobility to the greatest extent possible. Accordingly, a tremendous amount of research has been devoted to designing prosthetic components that replace the function of the anatomical limb, thereby minimizing gait impairments associated with highlevel limb loss (e.g., reduced walking speed [3-10], bilateral asymmetry [4,10-12], decreased balance [13-14], and increased energy expenditure $[9,15])$.

\footnotetext{
Abbreviations: $\mathrm{ANOVA}=$ analysis of variance, $\mathrm{ANT}=$ anterior alignment condition, ASIS = anterior superior iliac spine, $\mathrm{BASE}=$ baseline alignment condition, $\mathrm{GRF}=$ ground reaction force, $\mathrm{POST}=$ posterior alignment condition, $\mathrm{PSIS}=$ posterior superior iliac spine, $\mathrm{ROM}=$ range of motion, $\mathrm{VA}=$ Department of Veterans Affairs.

*Address all correspondence to Sara R. Koehler-McNicholas, PhD; Minneapolis VA Health Care System, One Veterans Dr (151), Minneapolis, MN 55417; 612-467-4017; fax: 612-725-2093. Email: sara.koehler@va.gov http://dx.doi.org/10.1682/JRRD.2014.12.0311
} 
Because of its structural complexity and multifunctional role during gait, the human knee joint is particularly difficult to replicate with a mechanically passive prosthetic component. Specifically, without muscles spanning the lower limb, persons with transfemoral amputation must learn to coordinate the movement of a passive prosthetic knee joint by implementing a control strategy that exploits the intersegmental coupling of their residual limb and prosthesis. To date, few studies have systematically explored the nature of these control strategies, particularly during the stance phase of gait, when inadequate control may lead to a sudden collapse of the knee joint and an increased risk of falling [13-14]. However, compensatory strategies at the ipsilateral hip joint and trunk have been identified as potential mechanisms by which persons with transfemoral amputation coordinate prosthetic knee flexion and extension [16-23]. Specifically, it is assumed that during early stance phase, persons with transfemoral amputation exert a hip extension moment to shift the ground reaction force (GRF) vector anterior to the knee joint center, thereby promoting knee extension for stable weight bearing. Conversely, it is assumed that during late stance phase, persons with transfemoral amputation exert a hip flexion moment to reorient the GRF vector so that it is posterior to the knee joint center, thereby triggering knee flexion in preparation for limb advancement [24]. Additionally, persons with transfemoral amputation may influence the GRF vector acting at their knee joint by altering the angle at which they place their prosthesis on the ground [25-26] or by varying their body center-of-mass position through postural adjustments of their trunk [27-30]. Understanding the association between these proximal control strategies and knee joint mechanics, and in particular the extent to which these strategies are used in isolation or in combination, may provide insight into the underlying mechanisms of prosthetic knee joint control and lead to better function and improved safety for individuals with transfemoral amputation.

To explore this association, one could implement a paradigm in which an intrinsic mechanical parameter of the knee joint is systematically perturbed and the biomechanical response of the person with transfemoral amputation is observed. In such an experiment, a response elicited by the perturbation may indicate a control strategy exploited by the individual to facilitate knee flexion or extension. Given its direct influence on knee joint mechanics, prosthetic alignment offers a systematic and clinically relevant way to manipulate the properties of the knee joint so as to understand the compensatory demands associated with its control. Prosthetic alignment, defined as the spatial arrangement of each component (i.e., socket, knee, foot) relative to one another, has important implications for the inherent stability of the prosthetic knee joint. In particular, the location of the prosthetic knee joint's center of rotation with respect to the GRF vector influences the moments applied to the joint during stance phase, and subsequently, the tendency for the knee to flex and extend under the weight of the user. Historically, prosthetists have been trained to follow an iterative procedure that relies on clinical experience and patient feedback when aligning a prosthetic limb. Prosthetists continually modify prosthetic alignment until they are satisfied that the patient exhibits few gait deviations and is comfortable. However, this process suffers from poor repeatability and little scientific justification. Furthermore, research has shown that although subjective feedback is necessary and informative, its contribution to the process of prosthetic alignment is somewhat limited given that users often accept a range of alignments and are only able to reliably perceive extreme misalignments [31-32]. To improve the process of transfemoral alignment and promote an objective basis for practice, researchers and clinicians must first acquire a better understanding of the relationship between variations in prosthetic alignment and the biomechanical response of the user.

The goal of this study was to characterize the short term, biomechanical response of persons with transfemoral amputation to perturbations in prosthetic knee joint alignment during a level walking task. To this end, we implemented a single-blinded, pseudorandomized crossover design in which we systematically varied the anterior-posterior position of a single-axis prosthetic knee joint to affect knee joint stability during the stance phase of gait. To fully characterize the user's response to changes in knee joint stability, we investigated a range of spatiotemporal, kinematic, and kinetic parameters that we selected based on previous studies of prosthetic alignment and on an empirical understanding of prosthetic knee joint control. We then compared these parameters between an anterior-posterior alignment condition and a baseline (i.e., bench alignment) condition. We hypothesized that in response to a destabilizing alignment perturbation (i.e., an anterior shift of the knee joint), participants would primarily increase their internal hip extension moment to maintain weight-bearing stability during early stance phase. We hypothesized that in response to a stabilizing alignment perturbation (i.e., a posterior shift of the knee joint), participants would primarily increase their internal hip flexion moment to initiate knee flexion in late stance 
phase. Given the fact that few studies have investigated transfemoral amputee gait in the context of prosthetic alignment, the results from this study have the potential to provide insight into the mechanisms available to persons with transfemoral amputation for prosthetic knee joint control.

\section{METHODS}

\section{Subjects}

Eleven participants with unilateral transfemoral amputation were recruited from the Northwestern University Prosthetics-Orthotics Center, the Rehabilitation Institute of Chicago, and local prosthetic clinics according to the following inclusion criteria: (1) age 18 to $65 \mathrm{yr}$; (2) body mass less than $115 \mathrm{~kg}$; (3) no known history of peripheral vascular disease or neurological/musculoskeletal disorders; (4) $3 \mathrm{yr}$ or more of experience with a definitive prosthesis; (5) ability to walk unaided on a treadmill at a constant, comfortable rate without undue fatigue or health risk; and (6) Medicare Functional Classification Level K3 ambulator or higher status (i.e., able to ambulate with variable cadence and able to traverse most environmental barriers). These criteria corresponded to the weight restrictions of the prosthetic components used in this study and the requirement of participants to complete a treadmill walking protocol. In an effort to recruit participants who could detect subtle changes in residual-limb loading associated with the different alignment conditions, participants at risk for sensory deficits (i.e., participants with peripheral vascular disease) were excluded from this study. Participants were also excluded if they reported persistent pain in their residual limb. Each participant was asked to rate his or her prosthetic socket according to a comfort scale described by Hanspal et al. [33]. This scale, which ranges from 0 (least comfortable) to 10 (most comfortable), is highly correlated with clinical assessments of socket fit and was used to screen participants for functional deficits associated with poor socket fit (defined in this study as a comfort score $\leq 4$ ).

Prior to testing, each participant underwent a physical examination to evaluate their residual-limb length, hip range of motion (ROM), and muscle strength. The same physical examiner, who had more than $20 \mathrm{yr}$ of experience in gait biomechanics, performed all of these evaluations. Residual-limb length was measured as the distance from the anterior superior iliac spine (ASIS) to the distal end of the residuum and was expressed as a ratio of the intact thigh length measured from the ASIS to the lateral femoral epicondyle. The degree of hip flexion contracture on the participant's affected side was measured using a Thomas test, administered with the participant in a supine position. A manual muscle test, described by Kendall et al. [34], was used to evaluate muscle strength for the following motions: bilateral hip flexion, extension, and abduction; intact knee flexion and extension; and intact ankle dorsiflexion and plantar flexion. Muscle strength was rated on a 6-point scale: $0=$ no contraction; $1=$ feeble contraction, no movement; 2 = ability to move through ROM in a horizontal plane; $3=$ ability to move through ROM against gravity; $4=$ resistance against moderate pressure; $4+=$ resistance against moderate to strong pressure; $5=$ resistance against strong pressure.

\section{Experimental Setup}

All data were collected at the Jesse Brown Department of Veterans Affairs (VA) Medical Center Motion Analysis Research Laboratory according to a single-day experiment that was divided into two sessions (setup and data acquisition). These sessions were separated by a $1 \mathrm{~h}$ break.

During the setup session, each participant practiced walking with their conventional prosthesis on a single-belt Cosmed Sport Treadmill (T170; Rome, Italy) equipped with several safety features, including an overhead safety harness and custom-made, adjustable handlebars. The safety harness secured participants against gravity and triggered a weight-activated emergency stop that arrested the movement of the treadmill belt in the event of a fall. The harness was fit with enough slack so that it did not restrict participants' normal trunk motion. Accordingly, it is unlikely that harnessing significantly influenced participants' normal gait pattern. While practicing on the treadmill, participants were instructed to use handlebars until they felt comfortable walking at their freely selected normal speed. As participants increased their comfort level, they were encouraged to swing their arms naturally at their sides. Participants practiced walking on the treadmill for approximately $15 \mathrm{~min}$, or until they felt comfortable. At the end of this practice session, the self-selected walking speed of each participant was recorded for use in subsequent data acquisition sessions.

Using the participant's existing prosthetic socket, a certified prosthetist fit all participants with a 3R95 single-axis knee joint (Ottobock; Duderstadt, Germany), a rigid pylon, and an Ottobock 1D35 Dynamic Motion foot (Figure 1). The Ottobock 3R95 knee joint was selected for this study because it is lightweight $(360 \mathrm{~g})$ and incorporates no 

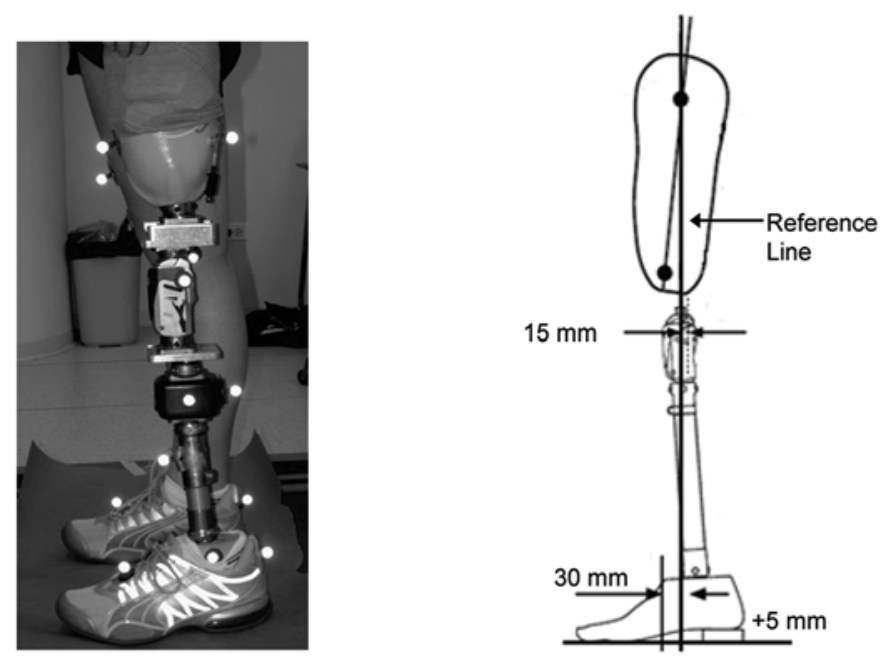

Figure 1.

Assembly of prosthesis and bench top alignment. To isolate knee translation, custom-made slide adapters were mounted proximal and distal to the prosthetic knee joint (left). The proximal slide adapter incorporated a slide plate on its top surface to facilitate bench alignment according to manufacturer's specifications (right, adapted from the Ottobock 3R95 owner's manual). Discrete settings on both the proximal and distal slide adapters accommodated anterior and posterior knee translation in $1 \mathrm{~cm}$ increments over a $4 \mathrm{~cm}$ range. As shown, the iPecs load cell was mounted between the pylon and distal slide adapter.

stance-phase control. The prosthesis was bench aligned according to manufacturer's specifications. Briefly, a vertical reference line was projected along the lateral aspect of the prosthesis, bisecting the socket wall at the level of the ischium. Socket flexion was preserved according to the assembly of the participant's existing prosthesis. A wedge was placed under the heel of the prosthetic foot, which created $5 \mathrm{~mm}$ of air space under the heel. The knee joint was aligned such that its mechanical axis fell $15 \mathrm{~mm}$ posterior to the vertical reference line; the foot was aligned such that its midline fell $30 \mathrm{~mm}$ anterior to the reference line. This alignment configuration established a consistent, interparticipant baseline alignment condition (BASE) from which all alignment adjustments were made (i.e., the prosthesis was not dynamically aligned). Resistance to swing-phase knee flexion and extension were independently set according to the participant's freely selected walking speed.

To vary knee alignment, a set of custom-made slide adapters $(900 \mathrm{~g})$ were mounted proximal and distal to the prosthetic knee joint, which allowed the knee to be trans- lated anterior and posterior in $1 \mathrm{~cm}$ increments over a $4 \mathrm{~cm}$ range. It should be noted that for each alignment condition, the relative position between the prosthetic socket, shank, and foot was held constant.

To measure forces and moments on the participant's affected side, a 6-degree-of-freedom iPecs load cell (College Park Industries Inc; Frasure, Michigan) was mounted in the participant's prosthesis, located between the distal slide adapter and the prosthetic pylon [35]. Data from the iPecs load cell were subsequently used in a quasistatic analysis to calculate hip and knee joint kinetics.

Finally, spherical, retroreflective markers $(12 \mathrm{~mm}$ diameter) were placed over the bony prominences of the participant's arms, legs, pelvis, and trunk according to a modified Helen Hayes full-body marker set [36]. Anatomical landmarks included the dorsum of each foot slightly proximal to the third metatarsal head, the posterior calcaneus at the height of the metatarsal marker, the lateral malleoli, the lateral femoral epicondyles, the left and right ASIS, the left posterior superior iliac spine (PSIS), the sacrum midway between the left and right PSIS, the tip of the acromion processes, the lateral epicondyles of the humerus, the wrists midway between the styloid processes, and the right scapula. With regard to the prosthesis, markers were placed on the axis of rotation of the knee joint and on the prosthetic foot and ankle at locations corresponding to the intact side. Five noncollinear wand markers were placed on the thigh and shank segments, and three markers were placed on the iPecs. The markers placed on the iPecs were centered on its medial, lateral, and posterior surfaces and corresponded to the load cell's instrumentation center and local coordinate system [35]. Four markers were also placed on the medial malleoli and medial epicondyles. These markers, used to calculate ankle and knee joint centers, were recorded in a static, standing trial and then removed.

\section{Experimental Protocol}

All participants completed three alignment conditions (BASE: bench alignment; anterior alignment condition [ANT]: $2 \mathrm{~cm}$ anterior knee translation; and posterior alignment condition [POST]: $2 \mathrm{~cm}$ posterior knee translation) according to a single-blinded, pseudorandomized crossover design (Figure 2). Together, these conditions comprised an extreme range of clinical adjustments and were comparable to previous studies of transfemoral prosthetic alignment [20-21,25]. Prior to data collection, participants were given an opportunity to walk overground ( $<5 \mathrm{~min})$ to 


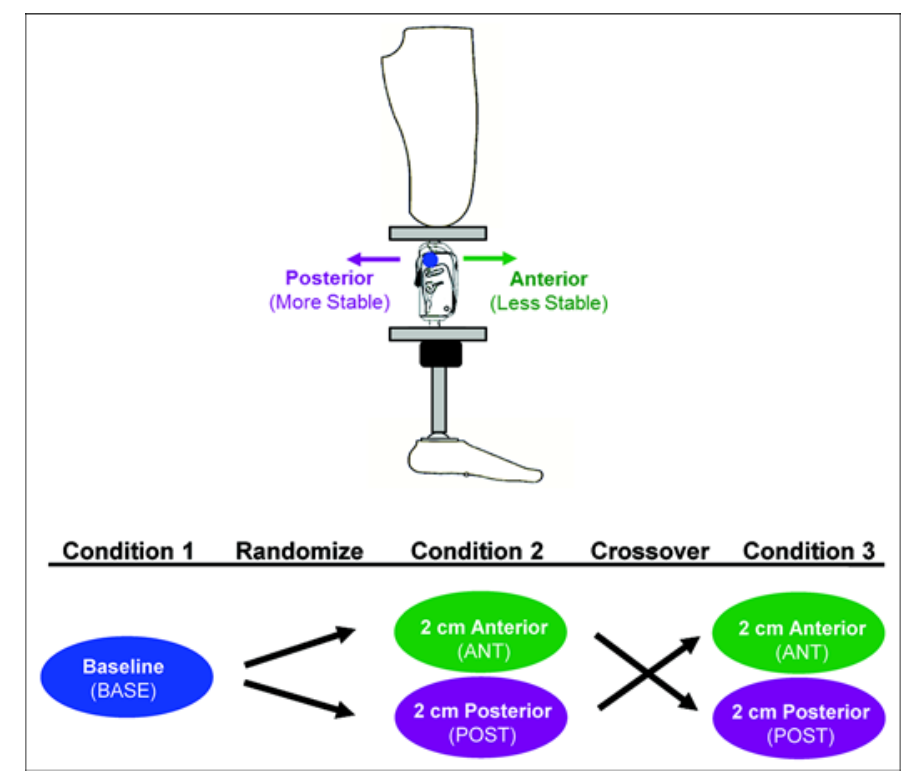

Figure 2.

Schematic flow of the single-blinded, pseudorandomized crossover design. As shown, socket, pylon, and foot orientation remained constant across the three alignment conditions. ANT = anterior alignment condition, BASE = baseline alignment condition, POST $=$ posterior alignment condition.

accommodate to the BASE. The iPecs was then zeroed in a vertical and off-weighted orientation. That is, participants were asked to stand with all of their weight on their intact limb, and the load cell was zeroed with the weight of the foot, shoe, and pylon suspended from its vertical axis. To ensure consistency between conditions, this procedure was repeated each time the prosthesis was aligned.

Beginning with BASE, participants were instructed to walk for $2.5 \mathrm{~min}$ at a self-selected speed on a level treadmill surface (harnessed and hands free). After 2 min of continuous walking, $30 \mathrm{~s}$ of quantitative gait data were recorded. Load cell data were sampled at $960 \mathrm{~Hz}$ and motion data were sampled at $120 \mathrm{~Hz}$ using an eight-camera, Eagle Digital RealTime motion capture system and Cortex 3.0 data acquisition software (Motion Analysis Corp, Santa Rosa, California). Load cell and motion data were synchronized to facilitate subsequent analyses.

This protocol was then repeated for both the ANT and POST in which the testing order was randomized and the walking speed was held constant. Participants were unaware of alignment perturbations; however, prior to walking on the treadmill, they were given an opportunity to walk overground ( $<5 \mathrm{~min}$ ). To minimize fatigue, par- ticipants were also allowed to rest between alignment conditions. Though most participants were able to complete the protocol as described, two participants were unable to swing their arms freely at their sides while walking on the treadmill. Instead, these two participants lightly placed their hands on side-mounted handlebars for added security. To minimize the influence of this strategy on lower-limb joint kinetics, they were instructed not to bear any weight through their arms.

\section{Data Analysis}

Cortex 3.0 software was used to track the threedimensional position of each marker relative to a global coordinate system (mean residual error $=1 \mathrm{~mm}$ ) and a built-in cubic-spline function was used to fill marker dropout ( $<5$ missing data points). To smooth coordinate trajectories, raw marker data were filtered off-line using a fourthorder, low-pass, bidirectional Butterworth filter with an effective cut-off frequency of $6 \mathrm{~Hz}$. Gait events (foot strike and toe off) were detected using Orthotrak 6.6.1 software (Motion Analysis Corp) and an extraction algorithm that monitored the resultant linear velocity of both the heel and toe markers. Orthotrak 6.6.1 was also used to calculate spatiotemporal parameters (walking speed, step length, stancephase duration) and three-dimensional joint kinematics according to a rigid-link segment model [36]. The global orientation of each body segment was described by an anatomical coordinate system in which the $x$-axis of the segment was directed from the proximal to the distal joint center (e.g., the $x$-axis for the thigh segment was directed from the hip joint center to the knee joint center), the $y$-axis was directed anterior to the segment, and the $z$-axis was directed lateral to the segment. The origin of the coordinate system was located at the proximal joint center. Intersegmental joint angles were calculated using the following Euler angle rotation sequence: flexion/extension, abduction/adduction, and internal/external rotation. Trunk and pelvis angles were calculated with respect to the global coordinate system. Using a cubic-spline function in MATLAB (R2010b, MathWorks; Natick, Massachusetts), kinematic data were normalized to 100 samples over stance phase and ensemble-averaged across all strides within each alignment condition. Strides in which the participant stumbled or fell were excluded from the analysis.

Because the prosthetic knee joint center was used to define the $x$-axis of the thigh and shank segments, alignment perturbations in which the knee joint was translated caused an offset in the flexion/extension angles at the hip, 
knee, and ankle, which did not correspond to actual joint rotation. Using a custom MATLAB program, flexion/ extension curves for the hip, knee, and ankle were adjusted according to the following equations:

$$
\begin{gathered}
\phi_{\text {hip }}=\theta_{\text {hip }}-\arctan \left(\Delta d / z_{\text {thigh }}\right), \\
\phi_{\text {knee }}=\theta_{\text {knee }}-\arctan \left(\Delta d / z_{\text {thigh }}\right)-\arctan \left(\Delta d / z_{\text {shank }}\right), \\
\phi_{\text {ankle }}=\theta_{\text {ankle }}-\arctan \left(\Delta d / z_{\text {shank }}\right),
\end{gathered}
$$

where $\Delta d$ represents the magnitude of the alignment shift (positive $=$ anterior); $z_{\text {thigh }}$ and $z_{\text {shank }}$ represent the vertical distance from the proximal joint center to the distal joint center of each segment measured during a static (i.e., standing) BASE; $\theta_{\text {hip }}, \theta_{\text {knee }}$, and $\theta_{\text {ankle }}$ represent the flexion/ extension angle for the hip, knee, and ankle (positive $=$ flexion) as measured by Orthotrak; and $\Phi_{h i p}, \Phi_{\text {knee }}$, and $\Phi_{\text {ankle }}$ represent the adjusted angles of the respective joints.

The sagittal-plane orientation of the thigh segment (i.e., inclination angle) on the affected side was evaluated using a custom MATLAB program. For this analysis, the thigh segment's coordinate system was oriented such that its long axis was directed from the hip joint center to the midpoint of two wand markers positioned at the same height on the anterior and posterior surfaces of the prosthetic socket. As described, this coordinate system was independent of the knee joint center and was therefore unaffected by variations in prosthetic knee alignment. Similar to the trunk and pelvis segments, the posture of the thigh segment was calculated relative to the global coordinate system.

Sagittal-plane joint moments for the knee and hip were calculated using iPecs load cell data and a quasistatic analysis. Load cell data were decimated to $120 \mathrm{~Hz}$ to match the sampling rate of the marker data. Force and moment signals were then low-pass filtered using a fourth-order, lowpass, bidirectional Butterworth filter with an effective cutoff frequency of $50 \mathrm{~Hz}$ [37-38]. Using a custom MATLAB program, forces and moments measured by the load cell $\left(\vec{F}_{i \text { Pecs }}^{\text {iPecs }}, \vec{M}_{i \text { Peccs }}^{\text {iPecs }}\right.$, were transformed into the global coordinate system $\left(\vec{F}_{\text {iPecs }}^{\text {Lab }}, \vec{M}_{\text {iPecs }}^{L a b}\right)$ :

$$
\vec{F}_{i P e c s}^{L a b}=\mathbf{R} \vec{F}_{i P e c s}^{i P e s},
$$

$$
\vec{M}_{i P e c s}^{L a b}=\mathbf{R} \vec{M}_{i P e c s}^{i P e c s}
$$

where $\mathbf{R}$, a $3 \times 3$ rotation matrix, represents the orientation of the load cell's coordinate system with respect to the global coordinate system. The columns of $\mathbf{R}$ correspond to the $x$-, $y$-, and $z$-axes of the load cell's coordinate system, which were defined according to the markers placed on the load cell's surface.

Once transformed into the global coordinate system, forces and moments measured at the instrumentation center of the iPecs were used to calculate sagittal-plane moments at the knee and hip joints. Briefly, a quasistatic analysis was used to calculate sagittal-plane forces and moments at the hip joint, expressed in a global coordinate system. Joint forces and moments were then transformed into the coordinate system of the distal body segment (e.g., hip forces and moments were expressed in the thigh coordinate system), normalized to 100 samples over stance phase, and ensemble-averaged across all strides within each alignment condition. It should be noted that although a quasistatic approach may differ slightly from a full inverse dynamics analysis, several studies have demonstrated its equivalency when inertial contributions to joint dynamics are minimal, for example, during the stance phase of gait and during slow walking speeds [6,26,39-42]. For this same reason, the increased mass of the prosthesis from the load cell and custom-made slide adapters likely had a negligible effect on stance-phase gait dynamics.

\section{Statistical Analysis}

All statistical analyses were performed using SPSS version 20.0 for Windows (IBM; Armonk, New York). For kinematic and kinetic time-series data, two points of interest were isolated for statistical analysis: (1) opposite toe off (i.e., the time point at which stance-phase stability is challenged by the transition from double support to independent weight bearing on the affected side) and (2) ipsilateral knee break (i.e., late-stance initiation of knee flexion). Diagnostic tests were conducted including Shapiro-Wilk test of normality, Mauchly test of sphericity, and Levene test of homogeneity of variance. When necessary, degrees of freedom were adjusted to correct for violations of sphericity [43] and homogeneity of variance. Given the normal distribution of difference scores, a two-way mixed analysis of variance (ANOVA) was performed with one betweengroup factor (testing order) and one within-group factor (alignment condition). In the event of a significant main 
effect $(p<0.05)$, post hoc Bonferroni multiple comparisons were used to assess statistical significance between BASE-ANT and BASE-POST $(p<0.025)$.

\section{RESULTS}

\section{Participant Demographics}

Table 1 summarizes participant demographics. Participants were relatively similar in terms of amputation etiology, socket type, and residual-limb length (Table 1), as well as socket fit, activity level, and bilateral muscle strength (Table 2). During manual muscle strength testing, all participants were able to resist either moderate or strong pressure in all tested planes of movement (Table 2). A small area of irritation on the residuum of one participant was noted; however, it did not interfere with the participant's regular daily activity. Furthermore, all participants considered their prosthetic socket to be comfortable (mean socket comfort score: $9 \pm 1$, range 6-10).

Table 1.

Participant demographics.

\begin{tabular}{|c|c|c|c|c|c|c|c|c|}
\hline Participant & Sex & Etiology & $\begin{array}{l}\text { Age } \\
\text { (yr) }\end{array}$ & $\begin{array}{c}\text { Height } \\
\text { (cm) }\end{array}$ & $\begin{array}{c}\text { Mass }^{*} \\
\text { (kg) }\end{array}$ & $\begin{array}{l}\text { Socket Type } \\
\text { (Suspension) }\end{array}$ & $\begin{array}{c}\text { Residuum } \\
\text { Length }^{\dagger}\end{array}$ & $\begin{array}{c}\text { Thomas } \\
\text { Test }\end{array}$ \\
\hline$\overline{1}$ & $\mathrm{M}$ & Trauma & 62 & 176.0 & 89.0 & IC (suction) & 0.90 & $15^{\circ}$ \\
\hline 3 & $\mathrm{~F}$ & Trauma & 51 & 173.5 & 70.8 & IC (liner/pin) & 0.75 & $15^{\circ}$ \\
\hline 4 & M & Trauma & 59 & 167.0 & 101.5 & IC (suction) & 0.96 & $0^{\circ}$ \\
\hline 5 & M & Trauma & 32 & 171.0 & 85.1 & IC (suction) & 0.83 & $15^{\circ}$ \\
\hline 7 & M & Trauma & 57 & 179.0 & 92.8 & sub-I (vacuum) & 0.87 & $10^{\circ}$ \\
\hline 8 & M & Cancer & 61 & 184.0 & 90.3 & IC (suction) & 0.74 & $10^{\circ}$ \\
\hline 9 & M & Trauma & 50 & 182.5 & 114.5 & IC (belt) & 0.59 & $0^{\circ}$ \\
\hline 10 & M & Cancer & 27 & 187.0 & 89.6 & sub-I (suction) & $\mathrm{KD}$ & $0^{\circ}$ \\
\hline 11 & M & Trauma & 29 & 178.5 & 86.0 & sub-I (vacuum) & 0.94 & $0^{\circ}$ \\
\hline
\end{tabular}

Table 2.

Manual muscle strength test.

\begin{tabular}{|c|c|c|c|c|c|c|c|c|c|c|c|}
\hline \multirow{2}{*}{ Limb } & \multicolumn{11}{|c|}{ Participant Number } \\
\hline & 1 & 2 & 3 & 4 & 5 & 6 & 7 & 8 & 9 & 10 & 11 \\
\hline \multicolumn{12}{|l|}{ Affected Limb } \\
\hline Hip Flexion: Supine, Flexed Hip & 5 & 5 & $4+$ & 5 & 5 & 5 & 5 & 5 & 5 & 5 & 5 \\
\hline Hip Extension: Prone & 5 & 5 & 5 & 5 & 5 & 5 & 5 & 5 & 5 & 5 & 5 \\
\hline Hip Abduction: Supine, Neutral Hip & 5 & 4 & $4+$ & 5 & 5 & 5 & 5 & 5 & 5 & 5 & 5 \\
\hline \multicolumn{12}{|l|}{ Intact Limb } \\
\hline Hip Extension: Prone, Knee Flexed $90^{\circ}$ & 5 & 5 & 5 & 5 & $4+$ & 5 & 5 & $4+$ & 5 & 5 & 5 \\
\hline Hip Abduction: Supine, Neutral Hip, Extended Knee & 5 & 5 & 5 & 5 & 5 & 5 & 5 & 5 & 5 & 5 & 5 \\
\hline Knee Flexion: Prone/Sitting & $4^{+} / 5$ & $5 / 5$ & $4^{+} / 5$ & $5 / 5$ & $4^{+} / 5$ & $5 / 5$ & $4^{+} / 5$ & $4^{+} / 5$ & $5 / 5$ & $5 / 5$ & $4 / 5$ \\
\hline Knee Extension: Sitting & 5 & 5 & 5 & 5 & 5 & 5 & 5 & 5 & 5 & 5 & 5 \\
\hline Ankle Dorsiflexion: Sitting & 5 & 5 & 5 & 5 & 5 & 5 & 5 & 5 & 5 & 5 & $4+$ \\
\hline
\end{tabular}


Of the 11 participants in this study, 5 followed a BASE-ANT-POST testing order and 6 followed a BASEPOST-ANT testing order. At least nine strides were analyzed for each of these conditions. A total of 210 strides were analyzed for BASE, 222 strides were analyzed for ANT, and 223 strides were analyzed for POST. It should be noted that hardware issues prevented the acquisition of load cell data for two participants. Thus, a subset of participants $(n=9)$ were used in a per-protocol analysis of kinetic data. It should also be noted that strides containing a stumble or fall were dropped from the data record (5 out of 210 strides for BASE, 7 out of 222 strides for ANT, and 1 out of 223 strides for POST). Most often, these falls, which were infrequent and distributed across six of the 11 participants, were associated with a sudden collapse of the knee joint during stance phase. Unless otherwise noted, all data are reported as mean \pm standard deviation.

\section{Spatiotemporal Characteristics}

Participants self-selected a comfortable walking speed of $0.8 \pm 0.2 \mathrm{~m} / \mathrm{s}$. Additional spatiotemporal characteristics are summarized in Table 3 . It should be noted that spatiotemporal characteristics were not significantly affected by testing order. However, the mixed ANOVA revealed a significant main effect of alignment on affectedside step length $(F(2,18)=4.464, p=0.023)$. For both BASE and POST participants demonstrated a slightly longer step length on their affected side compared with their intact side. Post hoc Bonferroni comparisons revealed that participants significantly decreased their affected-side step length in response to ANT ( $p=0.023)$ compared with BASE. Stance phase duration was shortest for ANT and longest for POST; however, across alignment conditions,

Table 3.

Mean \pm standard deviation spatiotemporal characteristics during level walking for the baseline, anterior, and posterior alignment conditions $(N=11)$.

\begin{tabular}{lccc}
\hline \multicolumn{1}{c}{ Characteristic } & BASE & ANT & POST \\
\hline Intact Limb Step Length (cm) & $52 \pm 7$ & $54 \pm 5$ & $53 \pm 6$ \\
Affected Limb & & & \\
$\quad$ Step Length (cm) & $54 \pm 8$ & $51 \pm 7^{*}$ & $55 \pm 8$ \\
Stance Phase (ms) & $874 \pm 115$ & $859 \pm 134$ & $884 \pm 123$ \\
$\quad$ Initial Double Support (ms) & $219 \pm 61$ & $238 \pm 75^{*}$ & $207 \pm 59$ \\
Single Support (ms) & $442 \pm 41$ & $426 \pm 50$ & $450 \pm 48$ \\
$\quad$ Terminal Double Support (ms) & $214 \pm 33$ & $196 \pm 31^{*}$ & $229 \pm 33^{*}$ \\
\hline
\end{tabular}

${ }^{*}$ Significant difference from BASE $(p<0.025)$.

$\mathrm{ANT}=$ anterior alignment condition, $\mathrm{BASE}=$ baseline alignment condition, POST $=$ posterior alignment condition . these results were not significantly different $(F(2,18)=$ $1.398, p=0.27)$. A significant effect of alignment was observed for the duration of both initial double support $(F(2,18)=8.949, p=0.002)$ and terminal double support $(F(2,18)=23.273, p<0.001)$, in which post hoc tests showed that initial double support phase was significantly longer for ANT compared to BASE $(p=0.022)$. In contrast, terminal double support phase was significantly shorter for ANT $(p=0.001)$ and significantly longer for POST $(p=0.007)$.

\section{Kinematics}

Sagittal-plane joint kinematics for the affected-side ankle, knee, and hip are summarized in Table 4 and Figure 3. Consistent with previous studies of transfemoral amputee gait, most participants maintained full knee extension from initial contact until shortly after opposite heel strike, at which point they initiated knee flexion in preparation for swing phase. Although not evident in the ensemble average curves in Figure 3, four participants demonstrated an inconsistent wave of stance-phase knee flexion during ANT, representing a movement toward knee collapse from which they were able to recover. Of the three participants who stumbled or fell during ANT, two demonstrated this inconsistent pattern of stancephase knee flexion.

Overall, participants exhibited a highly invariant pattern of sagittal-plane joint kinematics across all three alignment conditions, regardless of testing order. Statistical analyses revealed no significant differences in the magnitude of ankle, knee, or hip flexion at either opposite toe off or knee break (Table 4). A significant effect of alignment was observed for the orientation of the thigh at opposite toe off $(F(2,18)=9.655, p=0.001)$, such that for the ANT condition, participants maintained their affected limb in a more vertical posture compared to BASE ( $p=$ 0.002). Similarly, a significant effect of alignment was observed in the sagittal-plane posture of the trunk at opposite toe off $(F(2,18)=10.167, p=0.001)$ and knee break $(F(2,18)=8.063, p=0.003)$ as well as in the posture of the pelvis at opposite toe off $(F(2,18)=14.253, p<0.001)$ and knee break $(F(2,18)=7.547, p=0.004)$. Specifically, post hoc comparisons with BASE revealed a persistent increase in trunk flexion for ANT (Figure 4) at opposite toe off $(p=0.007)$ and knee break $(p=0.01)$. Likewise, during ANT, participants significantly increased their anterior pelvic tilt at opposite toe off $(p=0.002)$ and knee break $(p=0.01)$ compared with BASE. 
Table 4.

Mean \pm standard deviation affected-side joint kinematics at opposite toe off and knee break during level walking $(N=11)$.

\begin{tabular}{|c|c|c|c|c|c|c|}
\hline \multirow{2}{*}{ Joint } & \multicolumn{3}{|c|}{ Opposite Toe Off } & \multicolumn{3}{|c|}{ Knee Break } \\
\hline & BASE & ANT & POST & BASE & ANT & POST \\
\hline$\overline{\text { Ankle }}$ & $-3.9 \pm 2.4$ & $-3.2 \pm 2.5$ & $-3.9 \pm 2.5$ & $7.1 \pm 4.0$ & $7.7 \pm 4.2$ & $7.1 \pm 3.8$ \\
\hline Hip & $19.6 \pm 5.7$ & $21.1 \pm 5.6$ & $19.0 \pm 5.7$ & $-5.6 \pm 6.9$ & $-4.5 \pm 6.3$ & $-6.0 \pm 6.5$ \\
\hline Thigh & $3.0 \pm 2.3$ & $0.8 \pm 3.1^{*}$ & $2.8 \pm 2.3$ & $-20.7 \pm 3.2$ & $-22.2 \pm 3.3$ & $-21.1 \pm 3.2$ \\
\hline $\begin{array}{l}\text { Note: Positive } \\
\text { cates the dista } \\
\text { *Significant di } \\
\text { ANT = anteric }\end{array}$ & $\begin{array}{l}\text { dicate ankle d } \\
\text { e thigh is ante } \\
\text { rom BASE ( } p \\
\text { nt condition, E }\end{array}$ & $\begin{array}{l}\text {, knee flexion } \\
\text { proximal end } \\
\text { aseline alignm }\end{array}$ & on, $\mathrm{POST}=$ & nment condi & & \\
\hline
\end{tabular}

\section{Kinetics}

Kinetic data for the knee and hip joints are summarized in Table 5 and Figure 5. Although testing order did not significantly affect kinetic data, the mixed ANOVA revealed a significant main effect of alignment on the external extension moment measured at the knee joint at opposite toe off $(F(2,14)=65.871, p<0.001)$. Post hoc tests revealed that compared with BASE, the extension moment at the knee joint significantly decreased at opposite toe off for ANT $(p=0.02)$ and significantly increased at opposite toe off for POST $(p<0.001)$. These results correspond to a decrease in the margin of stability for ANT and an increase in the margin of stability for POST as participants transitioned to single-limb support on their affected side. Alignment also had a significant effect on the internal hip extension moment measured at opposite toe off $(F(2,14)=8.193, p=0.004)$ in which participants significantly increased their internal hip extension moment for ANT ( $p=0.019)$ compared with BASE. Interestingly, a significant difference was not observed in the hip extension moment at opposite toe off for POST and no significant post hoc differences were observed in the hip flexion moment required to break the knee in late stance.

\section{Ground Reaction Forces}

GRF data are summarized in Table 5 and Figure 6. Although the pattern of fore/aft GRF was similar across the three alignment conditions, a significant main effect of alignment was found for the fore/aft braking force at both opposite toe off $(F(2,14)=10.829, p=0.001)$ and knee break $(F(2,14)=21.496, p<0.001)$. Post hoc tests revealed that compared with BASE, the fore/aft braking force at opposite toe off significantly decreased for ANT $(p=0.009)$. In addition, the propulsive force at knee break significantly increased for ANT $(p=0.01)$ and significantly decreased for POST $(p=0.002)$ compared with BASE. No significant differences were observed in the vertical GRF profile at either opposite toe off or knee break.

\section{DISCUSSION}

The primary goal of this study was to characterize the underlying mechanisms associated with prosthetic knee joint control by investigating the short-term biomechanical response of persons with transfemoral amputation to systematic perturbations in knee joint alignment. We found that in response to a destabilizing alignment perturbation (i.e., an anterior shift in the knee joint), participants increased their internal hip extension moment to maintain extensor stability of the knee during early stance phase. Furthermore, we found that most participants simultaneously decreased the rate at which they loaded their prosthesis, decreased their affected-side step length, increased their trunk flexion, and maintained their prosthesis in a more vertical posture at the time of opposite toe off. This finding suggests that a hip torque strategy alone was perhaps insufficient to counteract the effect of the alignment perturbation and that persons with transfemoral amputation may instead rely on a combination of strategies to coordinate stancephase knee flexion and extension. The following sections describe these results in more detail, as well as the limitations and clinical implications of this study. 

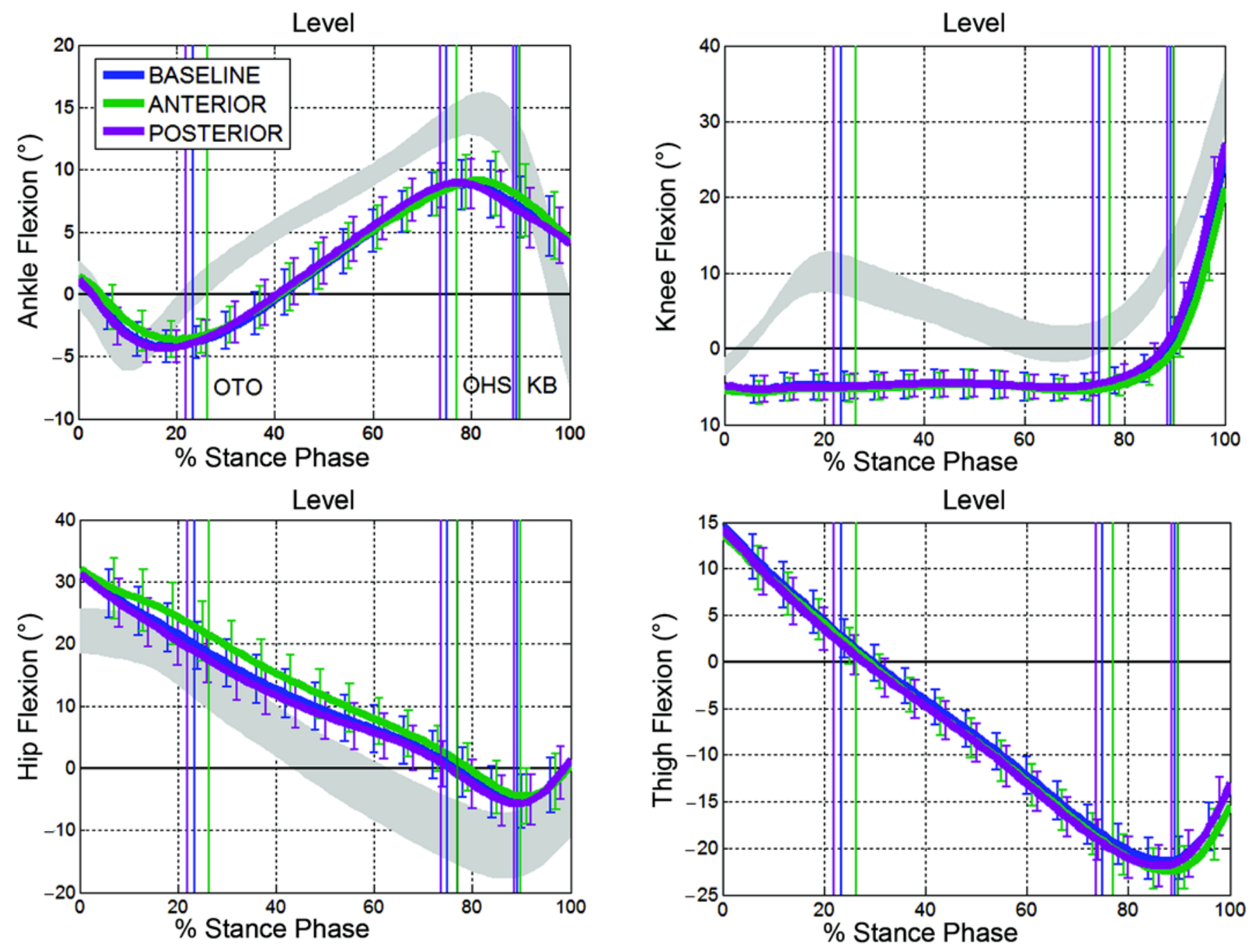

Figure 3.

Ensemble average of affected-side joint kinematics, shown with 95 percent confidence interval, for level walking $(N=11)$. Positive values indicate ankle dorsiflexion, knee flexion, and hip flexion. A positive thigh angle indicates that the distal end of the thigh is anterior to the proximal end. Gray bands correspond to speed-matched, reference data for nondisabled persons $(N=10)$. $\mathrm{KB}=\mathrm{knee}$ break, OTO = opposite toe off, OHS = opposite heel strike.

\section{Influence of Alignment Perturbation on Knee Joint Mechanics}

As expected, perturbations in prosthetic alignment had a significant effect on the external knee extension moment. Specifically, an anterior shift in the knee joint axis significantly decreased the external extension moment applied at the knee, and a posterior shift in the knee joint center significantly increased the external extension moment. To a large extent, this result corresponds to the fact that the moment arm between the GRF vector and the knee joint center was physically altered through the alignment perturbation. To explore the extent to which changes observed in the knee moment reflected changes in the lever arm only, we used a quasistatic analysis to calculate the expected moment at the knee joint using the forces and moments from BASE and the location of the knee joint center from ANT and POST. The results of this analysis are shown in Figure 5, as indicated by the black dashed lines. According to these results, the expected moment is similar to the actual moment measured for POST (shown in purple), indicating that participants did not significantly adjust their 

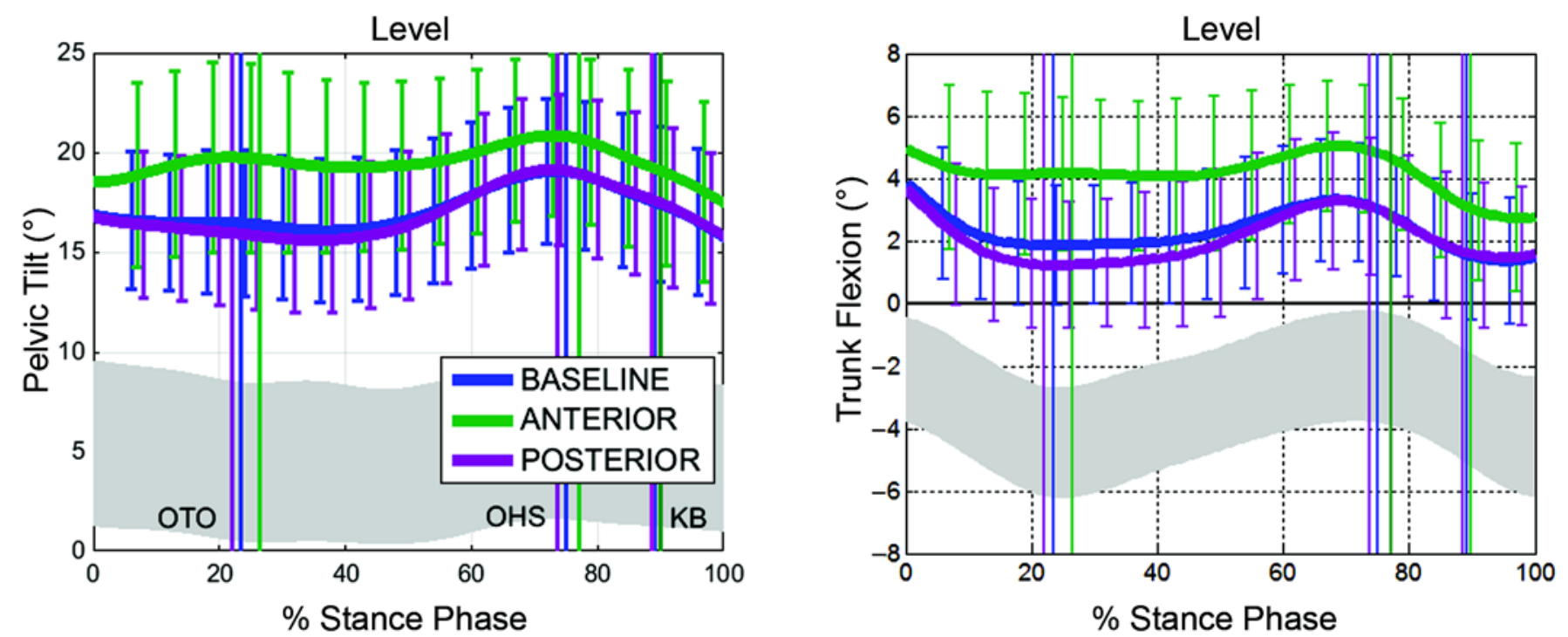

Figure 4.

Ensemble average of pelvis and trunk kinematics, shown with 95 percent confidence interval, for level walking $(N=11)$. Positive values indicate anterior pelvic tilt and trunk flexion. Gray bands correspond to speed-matched, reference data for nondisabled persons $(N=10) . K B=$ knee break, OTO = opposite toe off, OHS = opposite heel strike.

Table 5.

Mean \pm standard deviation affected-side joint kinetics and ground reaction force (GRF) at opposite toe off and knee break during level walking $(N=9)$.

\begin{tabular}{|c|c|c|c|c|c|c|}
\hline \multirow[b]{2}{*}{ Kinetic Variable } & \multicolumn{3}{|c|}{ Opposite Toe Off } & \multicolumn{3}{|c|}{ Knee Break } \\
\hline & BASE & ANT & POST & BASE & ANT & POST \\
\hline Knee Moment (Nm/kg) & $-0.13 \pm 0.08$ & $-0.08 \pm 0.07^{*}$ & $-0.30 \pm 0.08^{*}$ & $0.09 \pm 0.03$ & $0.08 \pm 0.03$ & $-0.04 \pm 0.04$ \\
\hline Fore/Aft GRF (N/kg) & $-0.05 \pm 0.04$ & $-0.02 \pm 0.04^{*}$ & $-0.06 \pm 0.04$ & $-0.04 \pm 0.01$ & $0.011 \pm 0.01^{*}$ & $-0.01 \pm 0.01^{*}$ \\
\hline Vertical GRF (N/kg) & $0.84 \pm 0.08$ & $0.84 \pm 0.08$ & $0.87 \pm 0.09$ & $0.38 \pm 0.21$ & $0.39 \pm 0.22$ & $0.35 \pm 0.21$ \\
\hline
\end{tabular}

gait pattern in response to POST. However, differences in the expected moment and the actual moment measured for ANT (shown in green) indicates that if participants had not adjusted their gait pattern, an external flexion moment at the knee joint would have resulted near the time of opposite toe off, potentially causing the knee joint to collapse.

\section{Early Stance Response to the Alignment Perturbation}

In response to ANT, participants exhibited changes in both their kinematic and kinetic gait patterns. As hypothesized, participants significantly increased their internal hip extension moment at opposite toe off, presumably in an effort to maintain the GRF vector anterior to the knee joint center. Indeed, the magnitude of the braking force also significantly decreased at opposite toe off, corresponding to an anterior tilt in the orientation of the resultant GRF vector. These results are consistent with two previous studies of transfemoral prosthetic alignment, in which an increase in the internal hip extension moment was observed in response to a $2 \mathrm{~cm}$ anterior shift in the knee joint center from an optimal alignment configuration [20-21]. Though hip torque strategies are currently considered the primary mechanism by which 

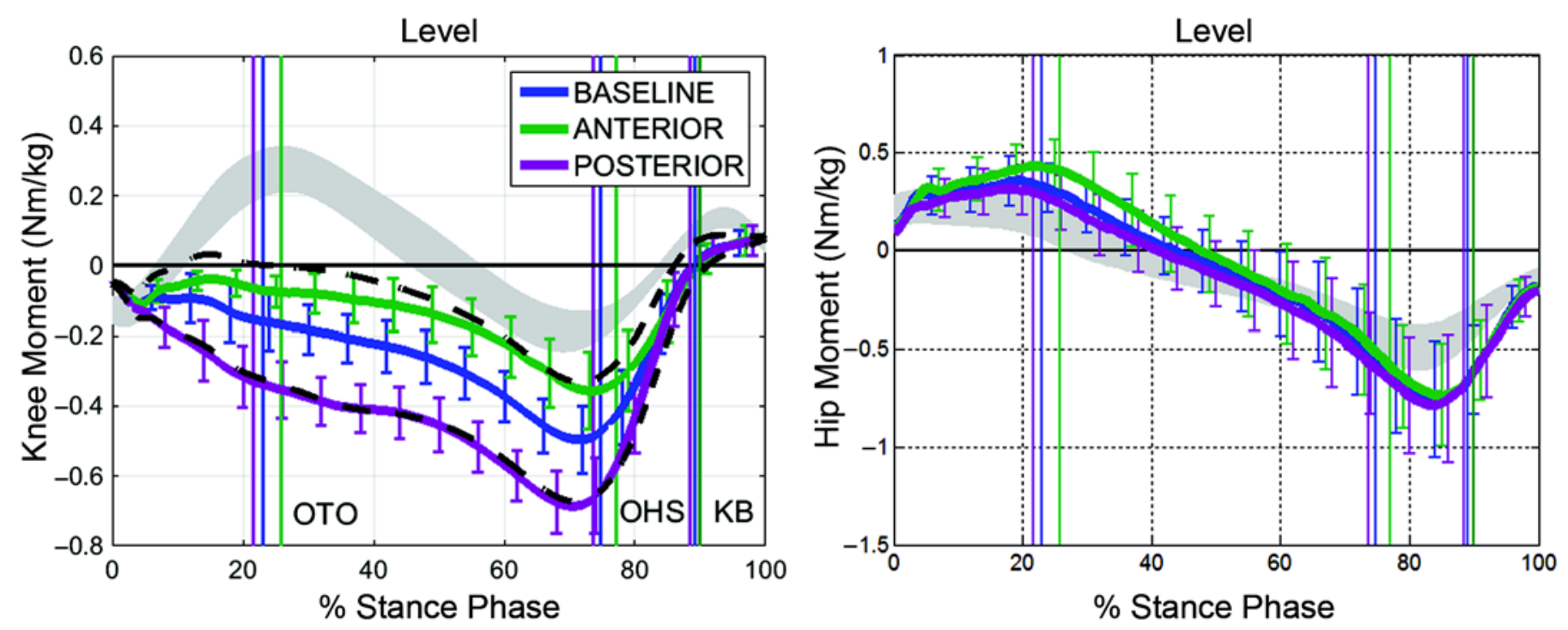

Figure 5.

Ensemble average of knee and hip kinetics for affected side, shown with 95 percent confidence interval, for level walking $(N=9)$. Positive values indicate an external knee flexion moment and an internal hip extension moment. Black dashed lines represent a theoretical scenario in which the load applied to the knee joint remains constant (i.e., corresponds to BASE) such that the resulting moment offset reflects a change in lever arm only. Gray bands correspond to speed-matched, reference data from nondisabled persons $(N=10)$. KB = knee break, OHS = opposite heel strike, OTO = opposite toe off.

persons with transfemoral amputation maintain extension of a passive prosthetic knee joint, few studies have systematically explored this relationship. Through the use of a systematic alignment perturbation, we found that participants did, in fact, rely on their hip extensors to stabilize the knee during early stance phase.

However, because participants also exhibited simultaneous changes in both spatiotemporal and kinematic parameters in response to ANT, it is difficult to determine the independence of these strategies. Specifically, as indicated by a significantly longer initial double support time, participants decreased the rate at which they loaded their prosthesis, which indicates a more tentative loading pattern [44]. Participants also significantly decreased their affected-side step length to the extent that their intact step length was relatively longer. This step length asymmetry is unusual for persons with unilateral amputation, who typically exhibit longer step lengths on their affected side [4,10-12]. To our knowledge, step length data have not been reported in previous studies of transfemoral prosthetic alignment. However, Yang observed that in response to an anterior shift in the knee joint center, participants decreased the inclination angle of their shank [25], poten- tially reducing their affected-side step length to decrease the braking force transmitted by the shank during early stance [45]. In this study, we also observed that participants significantly decreased the inclination angle of their affected limb, such that at opposite toe off, their limb was maintained in a more vertical posture. Assuming this strategy serves to reduce the braking force transmitted to the limb, it would potentially contribute to an increase in the affected hip extension moment. Furthermore, participants significantly increased trunk flexion, which was accompanied by an increase in anterior pelvic tilt at the time of opposite toe off. Previous studies of nondisabled individuals have shown an association between trunk flexion and hip extension moments [46], such that an increase in trunk flexion may enhance knee joint stability [29-30]. However, to our knowledge, this study is the first to quantify changes in trunk flexion as a mechanism to stabilize a passive prosthetic knee joint for persons with transfemoral amputation.

Collectively, these results are consistent with our hypothesis and indicate that participants significantly increased their internal hip extension moment at opposite toe off in response to ANT. However, participants also 

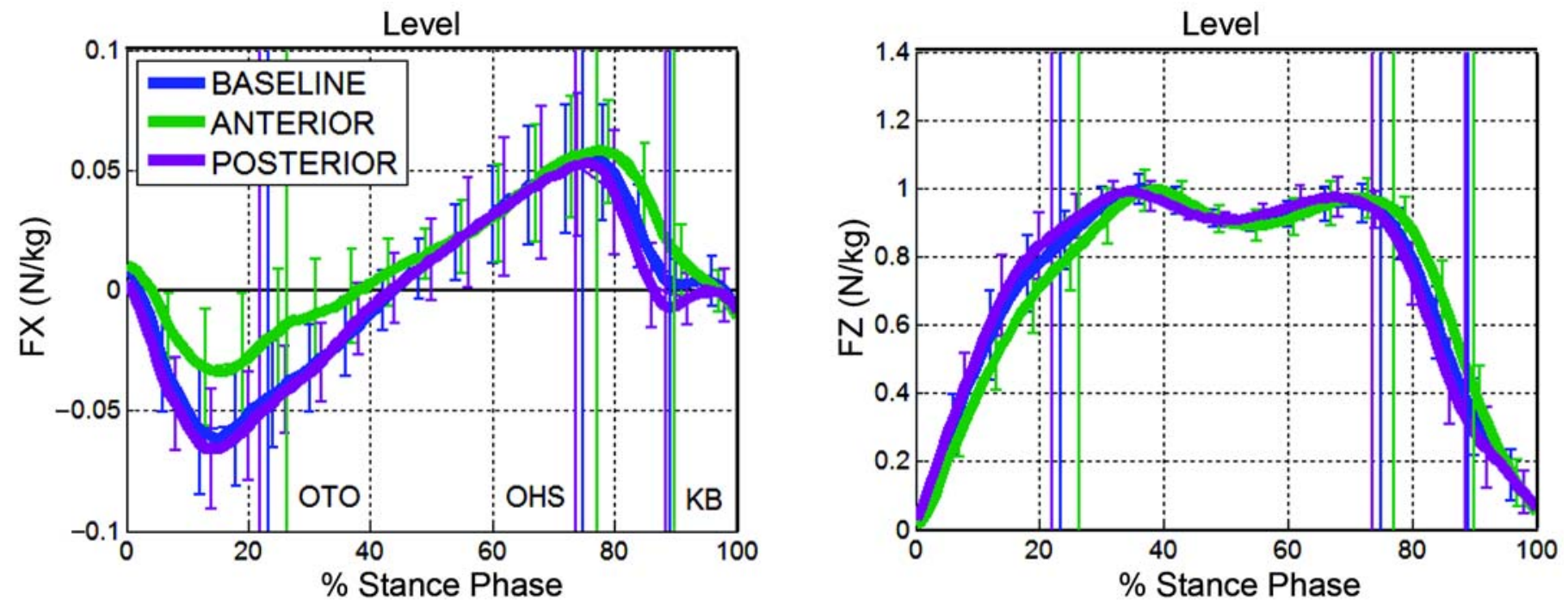

Figure 6.

Ensemble average of fore/aft (FX) and vertical (FZ) ground reaction force data, shown with 95 percent confidence interval, for level walking $(N=9)$. Positive value of $\mathrm{FX}$ indicates a propulsive force. $\mathrm{KB}=$ knee break, $\mathrm{OHS}=$ opposite heel strike, OTO = opposite toe off.

exhibited subtle changes in spatiotemporal and kinematic gait parameters that make it difficult to determine the independence of these strategies. Of the nine participants for which we collected both kinematic and kinetic data, seven exhibited the combined strategy of increased hip extension moment, increased trunk flexion, and decreased inclination angle of the prosthesis. Of the remaining two participants, one maintained an invariant kinetic/kinematic strategy and one increased their internal hip extension moment despite a decrease in trunk flexion. This finding suggests that although a hip torque strategy alone may be an effective method of control, perhaps it is more metabolically efficient to simultaneously involve both kinematic and kinetic adjustments. Of course, this interpretation is speculative and requires future work to isolate the metabolic cost of different control strategies.

\section{Late-Stance Response to Alignment Perturbation}

Unexpectedly, variations in prosthetic knee joint alignment did not significantly influence the internal hip flexion moment required to initiate knee flexion in late stance. At first, this result seems counterintuitive, since in order for knee break to occur, it would seem the GRF vector would have to pass through a more posterior-located knee joint center. This action would in turn result in a larger moment arm acting at the hip joint ( $\mathrm{r}_{\text {hip }}$ ), corresponding to a larger hip flexion moment (Figure 7). However, if the magnitude of the GRF vector decreased to offset a larger moment arm, it would follow that the net moment at the hip joint would remain constant. Indeed, we observed that at the time of knee break, the magnitude of the propulsive component of the GRF vector was significantly larger for ANT and significantly smaller for POST, corresponding to the scenario depicted in Figure 7. Likewise, the magnitude of the vertical GRF vector was larger for ANT and smaller for POST, although this trend was not statistically significant. We believe that instead of responding to POST by increasing their hip flexion moment, participants maintained an invariant loading pattern during late stance and allowed the GRF vector to sweep across the prosthetic knee joint center slightly later during stance phase. In other words, knee break was delayed (Figure 3). This interpretation is supported by the fact that the terminal double support phase was significantly longer for POST and significantly shorter for ANT. Similar results have been reported for knee joints with different stability properties [47].

The consequences of such a strategy were not quantified in this study. Presumably, a shift in the timing of knee break may have implications for swing phase. For example, in response to this strategy, swing-phase knee flexion may be reduced such that toe clearance is compromised. 


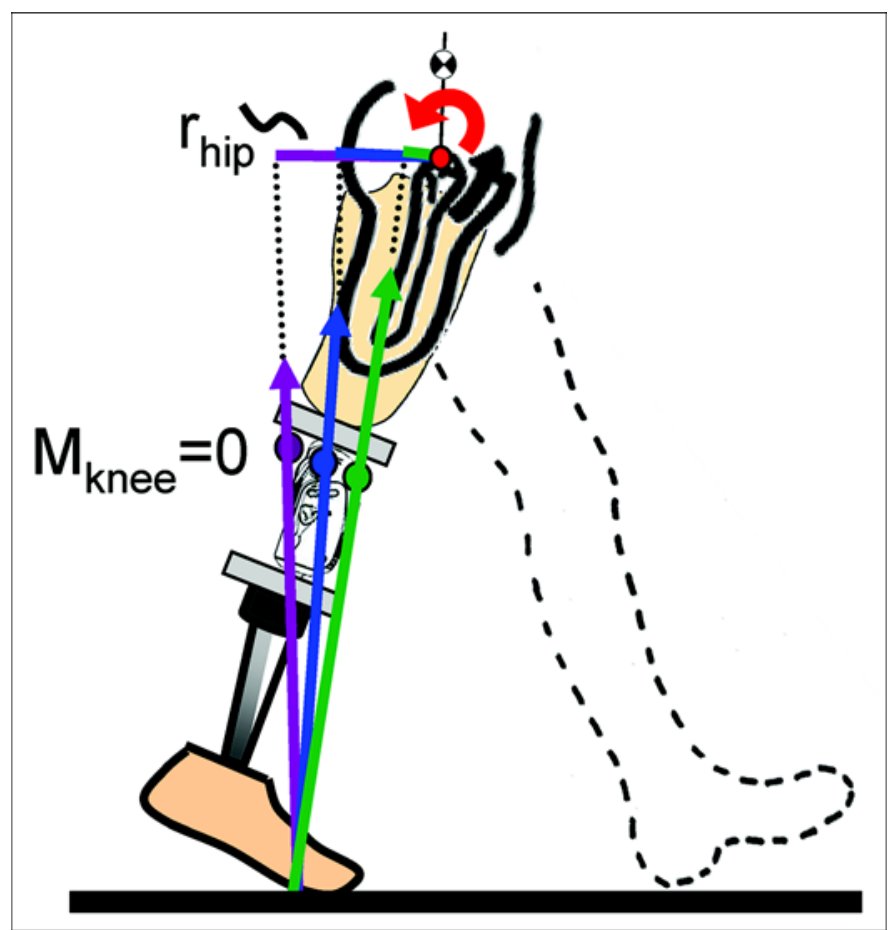

Figure 7.

Depiction of the prosthesis during late stance and the influence of prosthetic alignment (blue $=$ baseline, green $=$ anterior, purple $=$ posterior) on the sagittal-plane hip ( $\left.r_{h i p}\right)$ and knee moment $\left(M_{k n e e}\right)$.

Previous studies of transfemoral amputee gait have shown that participants compensate for insufficient knee flexion during swing phase by circumducting their affected-side hip and plantar flexing their intact ankle [24,48]. Therefore, we might expect one or both of these compensatory strategies to manifest during swing phase with POST. To confirm this hypothesis, future studies should investigate the influence of prosthetic alignment on swing phase mechanics.

\section{Limitations}

When interpreting the results of this study, it is important to note several limitations. First, the participants investigated in this study comprised a relatively homogeneous sample of transfemoral prosthesis users with similar activity levels, amputation etiologies, residual-limb lengths, and residual-limb muscle strength. Caution should therefore be exercised when generalizing these results to a broader population of users whose potential to adapt to changes in knee joint mechanics may be limited by sensory deficits (e.g., individuals with peripheral neuropathy and vascular disease), poor socket fit, and residual-limb muscle weakness.

Second, although the use of a treadmill offered several practical advantages in this study (e.g., the option to harness participants as a safety precaution and the ability to collect continuous walking data), it also introduced some limitations. One of these limitations relates to the contrast between treadmill walking and overground walking. Indeed, previous studies have examined participants in both tasks and have found similarities [49-51] and differences [52-54]. Because we were interested in relative changes between alignment conditions, we contend that although the absolute value of kinematic or kinetic variables may have differed from overground walking, it is likely that the same relative changes in response to alignment would have been observed. Of course, additional work is needed to resolve this issue.

The extent to which treadmill walking constrained walking speed may also be considered a limitation in this study. Though it was advantageous to control walking speed to minimize its effect on kinematic and kinetic data, it is possible that some participants may have preferred to adjust their walking speed in response to changes in alignment. Furthermore, participants may have adjusted their intact-side biomechanics, which was not assessed in this study. Accordingly, the effect of prosthetic alignment on both walking speed and intact side joint kinematics and kinetics remain as areas for future investigation.

Another limitation in this study involves the duration of adaptation. Following each alignment condition, participants were given an opportunity to walk overground ( $<5 \mathrm{~min}$ ). They then walked for $2 \mathrm{~min}$ on the treadmill before a $30 \mathrm{~s}$ interval of quantitative gait data was acquired. Accordingly, participants had little time to adapt to each alignment condition, which raises a question as to whether the results from this study correspond to a steadystate strategy. Though the time course for adaptation to prosthetic alignment has not been previously reported, related studies suggest that persons with amputation [55] and ambulators without disabilities [56] can quickly adapt ( $<5 \mathrm{~min}$ ) to novel changes in lower-limb inertia. In fact, a more rigorous investigation of adaptation has shown that ambulators without disabilities can achieve steady-state joint kinematics within 40 to 50 strides [57]. Therefore, we believe the adaptation period used in this study was sufficient to address our hypotheses.

With regard to the stabilizing alignment perturbation, a posterior shift of $2 \mathrm{~cm}$ may have been insufficient to elicit 
a consistent response among our participant population. Had we used a larger posterior perturbation, participants may have been forced to compensate for the increase in alignment stability. Indeed, in two previous studies of prosthetic alignment, participants increased their hip flexion moment in late stance in response to a posterior alignment perturbation [20-21]. However, an important difference between these studies and our study is the method by which BASE was established. In the studies by Blumentritt et al. [20] and Schmalz et al. [21], optimal alignment, as defined by a prosthetist, was used as the BASE. Accordingly, participants progressed through a different range of alignment perturbations, such that certain participants who started with a more stable alignment may have biased the results. In our study, we established a consistent BASE (i.e., bench alignment as described by the manufacturer) such that all participants progressed through an identical range of alignment perturbations. However, depending on their physical capabilities, this range may have challenged participants differently.

\section{CONCLUSIONS}

Participants responded to a destabilizing alignment perturbation by increasing their hip extension moment during early stance phase, which confirmed our hypothesis that persons with transfemoral amputation rely on a hip extensor strategy to maintain knee joint stability. However, participants also decreased the rate at which they loaded their prosthesis, decreased their affected-side step length, increased their trunk flexion, and maintained their prosthesis in a more vertical posture at the time of opposite toe off, suggesting that a hip torque strategy alone was perhaps insufficient to counteract the effect of the alignment perturbation. Although we hypothesized that participants would respond to a stabilizing alignment by increasing their hip flexion moment to initiate knee break during late stance, our results did not support this hypothesis. Instead, knee break was delayed for POST. From a clinical perspective, these results suggest that a bias toward posterior alignment may have fewer implications for the patient in terms of knee joint control. However, it is possible that an overly stable knee joint may also have negative consequences for swing phase. To our knowledge, this is the first systematic study of prosthetic knee joint alignment in which lower-limb and trunk kinematics were investigated in conjunction with sagittal- plane hip and knee kinetics to understand the mechanisms of prosthetic knee joint control. Accordingly, we believe the results from this study may provide new insights into the biomechanical mechanisms contributing to the sagittal stability and control of a passive prosthetic knee joint.

\section{ACKNOWLEDGMENTS}

\section{Author Contributions:}

Study concept and design: S. R. Koehler-McNicholas, R. D. Lipschutz, S. A. Gard.

Acquisition of data: S. R. Koehler-McNicholas, R. D. Lipschutz. Analysis and interpretation of data: S. R. Koehler-McNicholas, R. D. Lipschutz, S. A. Gard.

Drafting of manuscript: S. R. Koehler-McNicholas.

Critical revision of manuscript for important intellectual content: S. R. Koehler-McNicholas, R. D. Lipschutz, S. A. Gard.

Statistical analysis: S. R. Koehler-McNicholas.

Obtained funding: S. R. Koehler-McNicholas, S. A. Gard.

Study supervision: S. A. Gard.

Financial Disclosures: The authors have declared that no competing interests exist.

Funding/Support: This material was based on work supported by the VA, Office of Research and Development, Rehabilitation Research and Development Service (award VA RR\&D RX000143) and was administered by the Jesse Brown VA Medical Center, Chicago, Illinois. This research was also partially funded by the Orthotics and Prosthetics Education and Research Foundation (grant OPERF-2009-FA-12) and the National Institute on Disability and Rehabilitation Research (NIDRR) of the U.S. Department of Education (grant H133E080009; Principal Investigators: Steven Gard and Stefania Fatone).

Additional Contributions: The authors would like to thank Rebecca Stine, MS, for assistance with data collection; Ryan Caldwell, CP, for help with participant recruitment; Mark Edwards, CP, for early feedback on study design; Edward Grahn and Dilip Thacker for machining the slide adapter used in this study design; Yasin Dhaher, $\mathrm{PhD}$, for assistance with data analysis; Andrew Hansen, $\mathrm{PhD}$, for manuscript preparation; and Michael Kuskowski, $\mathrm{PhD}$, for statistical support. The work described in this article was conducted at the Northwestern University Prosthetics-Orthotics Center. S. R. Koehler-McNicholas is now affiliated with the Minneapolis VA Health Care System, Minneapolis, Minnesota.

Institutional Review: All experimental procedures were approved by the Northwestern University Institutional Review Board or the Jesse Brown VA Medical Center Institutional Review Board, and each participant signed a consent form prior to participation in this study.

Participant Follow-Up: The authors do not plan to inform participants of the publication of this study. However, participants have been encouraged to check the Northwestern University Prosthetics-Orthotics Center Web site for updated publications related to the program's activities, which include the present study. 
Disclaimer: The opinions contained in this publication are those of the grantee and do not necessarily reflect those of the Department of Education or VA.

\section{REFERENCES}

1. Esquenazi A. Amputation rehabilitation and prosthetic restoration. From surgery to community reintegration. Disabil Rehabil. 2004;26(14-15):831-6. [PMID:15497912] http://dx.doi.org/10.1080/09638280410001708850

2. Ziegler-Graham K, MacKenzie EJ, Ephraim PL, Travison TG, Brookmeyer R. Estimating the prevalence of limb loss in the United States: 2005 to 2050. Arch Phys Med Rehabil. 2008;89(3):422-9. [PMID:18295618] http://dx.doi.org/10.1016/j.apmr.2007.11.005

3. Jaegers SM, Arendzen JH, de Jongh HJ. Prosthetic gait of unilateral transfemoral amputees: A kinematic study. Arch Phys Med Rehabil. 1995;76(8):736-43. [PMID:7632129] http://dx.doi.org/10.1016/S0003-9993(95)80528-1

4. Murray MP, Sepic SB, Gardner GM, Mollinger LA. Gait patterns of above-knee amputees using constant-friction knee components. Bull Prosthet Res. 1980;10-34:35-45. [PMID:7260459]

5. Boonstra AM, Schrama J, Fidler V, Eisma WH. The gait of unilateral transfemoral amputees. Scand J Rehabil Med. 1994;26(4):217-23. [PMID:7878397]

6. Cappozzo A, Figura F, Leo T, Marchetti M. Biomechanical evaluation of above-knee prostheses. In: Komi PV, editor. Biomechanics VA. Baltimore (MD): University Park Press; 1976. p. 366-72.

7. Eakin CL, Quesada PM, Skinner H. Lower-limb proprioception in above-knee amputees. Clin Orthop Relat Res. 1992;(284):239-46. [PMID:1395300]

8. Huang CT, Jackson JR, Moore NB, Fine PR, Kuhlemeier KV, Traugh GH, Saunders PT. Amputation: Energy cost of ambulation. Arch Phys Med Rehabil. 1979;60(1):18-24. [PMID:420566]

9. Waters RL, Perry J, Antonelli D, Hislop H. Energy cost of walking of amputees: The influence of level of amputation. J Bone Joint Surg Am. 1976;58(1):42-6. [PMID:1249111] http://dx.doi.org/10.2106/00004623-197658010-00007

10. James U, Oberg K. Prosthetic gait pattern in unilateral above-knee amputees. Scand J Rehabil Med. 1973;5(1): 35-50. [PMID:4804043]

11. van der Linden ML, Solomonidis SE, Spence WD, Li N, Paul JP. A methodology for studying the effects of various types of prosthetic feet on the biomechanics of trans-femoral amputee gait. J Biomech. 1999;32(9):877-89.

[PMID:10460124] http://dx.doi.org/10.1016/S0021-9290(99)00086-X
12. Yiğiter K, Sener G, Erbahçeci F, Bayar K, Ulger OG, Akdoğan $\mathrm{S}$. A comparison of traditional prosthetic training versus proprioceptive neuromuscular facilitation resistive gait training with trans-femoral amputees. Prosthet Orthot Int. 2002;26(3):213-7. [PMID:12562068] http://dx.doi.org/10.1080/03093640208726650

13. Miller WC, Deathe AB, Speechley M, Koval J. The influence of falling, fear of falling, and balance confidence on prosthetic mobility and social activity among individuals with a lower extremity amputation. Arch Phys Med Rehabil. 2001;82(9):1238-44. [PMID:11552197] http://dx.doi.org/10.1053/apmr.2001.25079

14. Kulkarni J, Toole C, Hirons R, Wright S, Morris J. Falls in patients with lower limb amputations: Prevalence and contributing factors. Physiotherapy. 1996;82(2):130-6. http://dx.doi.org/10.1016/S0031-9406(05)66968-4

15. Waters RL, Yakura JS. The energy expenditure of normal and pathologic gait. Crit Rev Phys Rehabil Med. 1989; 1(3):183-209.

16. DiAngelo DJ, Winter DA, Ghista DN, Newcombe WR. Performance assessment of the Terry Fox jogging prosthesis for above-knee amputees. J Biomech. 1989;22(6-7):

543-58. [PMID:2808440] http://dx.doi.org/10.1016/0021-9290(89)90006-7

17. Czerniecki JM. Rehabilitation in limb deficiency. 1. Gait and motion analysis. Arch Phys Med Rehabil. 1996;77(3, Suppl):S3-8. [PMID:8599543] http://dx.doi.org/10.1016/S0003-9993(96)90236-1

18. Seroussi RE, Gitter A, Czerniecki JM, Weaver K. Mechanical work adaptations of above-knee amputee ambulation. Arch Phys Med Rehabil. 1996;77(11):1209-14. [PMID:8931539] http://dx.doi.org/10.1016/S0003-9993(96)90151-3

19. Silver-Thorn MB, Glaister C. Functional stability of transfemoral amputee gait using the 3R80 and Total Knee 2000 prosthetic knee units. J Prosthet Orthot. 2009;21(1):18-31. http://dx.doi.org/10.1097/JPO.0b013e318195b917

20. Blumentritt S, Scherer HW, Michael JW, Schmalz T. Transfemoral amputees walking on a rotary hydraulic prosthetic knee mechanism: A preliminary report. J Prosthet Orthot. 1998;10(3):61-70. http://dx.doi.org/10.1097/00008526-199801030-00005

21. Schmalz T, Blumentritt S, Jarasch R. Energy expenditure and biomechanical characteristics of lower limb amputee gait: The influence of prosthetic alignment and different prosthetic components. Gait Posture. 2002;16(3):255-63. [PMID:12443950] http://dx.doi.org/10.1016/S0966-6362(02)00008-5

22. Radcliffe CW. The Knud Jansen Lecture: Above-knee prosthetics. Prosthet Orthot Int. 1977;1(3):146-60. [PMID:617371] 
23. Pejhan S, Farahmand F, Parnianpour M. Design optimization of an above-knee prosthesis based on the kinematics of gait. Conf Proc IEEE Eng Med Biol Soc. 2008;2008:4274-7. [PMID:19163657] http://dx.doi.org/10.1109/IEMBS.2008.4650154

24. van Keeken HG, Vrieling AH, Hof AL, Postema K, Otten B. Principles of obstacle avoidance with a transfemoral prosthetic limb. Med Eng Phys. 2012;34(8):1109-16. [PMID:22197358] http://dx.doi.org/10.1016/j.medengphy.2011.11.017

25. Yang L, Solomonidis SE, Spence WD, Paul JP. The influence of limb alignment on the gait of above-knee amputees. J Biomech. 1991;24(11):981-97. [PMID:1761584] http://dx.doi.org/10.1016/0021-9290(91)90016-G

26. van Keeken HG, Vrieling AH, Hof AL, Postema K, Otten B. Stabilizing moments of force on a prosthetic knee during stance in the first steps after gait initiation. Med Eng Phys. 2012;34(6):733-9. [PMID:21996358]

http://dx.doi.org/10.1016/j.medengphy.2011.09.017

27. Perry J. Gait analysis: Normal and pathological function. 1st ed. Thorofare, (NJ): SLACK; 1992. 524 p.

28. Whittle MW. Gait analysis: An introduction. 3rd ed. Woburn (MA): Reed Educational and Professional Publishing; 2001. 232 p.

29. Shumway-Cook A, Woollacott M. Motor control: Translating research into clinical practice. 4th ed. Baltimore (MD): Lippincott Williams \& Wilkins; 2012. 656 p.

30. Edelstein J, Moroz A. Lower-limb prosthetics and orthotics: Clinical concepts. Thorofare (NJ): SLACK; 2011. 208 p.

31. Zahedi MS, Spence WD, Solomonidis SE, Paul JP. Alignment of lower-limb prostheses. J Rehabil Res Dev. 1986; 23(2):2-19. [PMID:3723422]

32. Boone DA. Investigation of socket reactions from transtibial prosthesis malalignment [dissertation]. [Hong Kong]: The Hong Kong Polytechnic University; 2005. 272 p.

33. Hanspal RS, Fisher K, Nieveen R. Prosthetic socket fit comfort score. Disabil Rehabil. 2003;25(22):1278-80. [PMID:14617445] http://dx.doi.org/10.1080/09638280310001603983

34. Kendall FP, McCreary EK, Provance PG, Rodgers MM, Romani WA. Muscles: Testing and function with posture and pain. 5th ed. Baltimore (MD): Lippincott Williams \& Wilkins; 2005. 560 p.

35. Koehler SR, Dhaher YY, Hansen AH. Cross-validation of a portable, six-degree-of-freedom load cell for use in lowerlimb prosthetics research. J Biomech. 2014;47(6):1542-7. [PMID:24612723] http://dx.doi.org/10.1016/j.jbiomech.2014.01.048

36. Kadaba MP, Ramakrishnan HK, Wootten ME. Measurement of lower extremity kinematics during level walking. J Orthop Res. 1990;8(3):383-92. [PMID:2324857] http://dx.doi.org/10.1002/jor.1100080310
37. Antonsson EK, Mann RW. The frequency content of gait. J Biomech. 1985;18(1):39-47. [PMID:3980487]

http://dx.doi.org/10.1016/0021-9290(85)90043-0

38. Simon SR, Paul IL, Mansour J, Munro M, Abernethy PJ, Radin EL. Peak dynamic force in human gait. J Biomech. 1981;14(12):817-22. [PMID:7328088] http://dx.doi.org/10.1016/0021-9290(81)90009-9

39. Wells RP. The projection of the ground reaction force as a predictor of internal joint moments. Bull Prosthet Res. 1981;10(35):15-9. [PMID:7332827]

40. Miller LA, Childress DS. Problems associated with the use of inverse dynamics in prosthetic applications: An example using polycentric prosthetic knees. Robotica. 2005;23:329_ 35. http://dx.doi.org/10.1017/S0263574704001353

41. Hof AL. On the interpretation of the support moment. Gait Posture. 2000;12(3):196-9. [PMID:11154929] http://dx.doi.org/10.1016/S0966-6362(00)00084-9

42. $\mathrm{Wu} \mathrm{G}$, Ladin Z. Limitations of quasi-static estimation of human joint loading during locomotion. Med Biol Eng Comput. 1996;34(6):472-6. [PMID:9039751] http://dx.doi.org/10.1007/BF02523853

43. Greenhouse SW, Geisser S. On methods in the analysis of profile data. Psychometrika. 1959;24:95-112. http://dx.doi.org/10.1007/BF02289823

44. Heiden TL, Sanderson DJ, Inglis JT, Siegmund GP. Adaptations to normal human gait on potentially slippery surfaces: The effects of awareness and prior slip experience. Gait Posture. 2006;24(2):237-46. [PMID:16221549] http://dx.doi.org/10.1016/j.gaitpost.2005.09.004

45. Martin PE, Marsh AP. Step length and frequency effects on ground reaction forces during walking. J Biomech. 1992; 25(10):1237-9. [PMID:1400525] http://dx.doi.org/10.1016/0021-9290(92)90081-B

46. Leteneur S, Gillet C, Sadeghi H, Allard P, Barbier F. Effect of trunk inclination on lower limb joint and lumbar moments in able men during the stance phase of gait. Clin Biomech (Bristol, Avon). 2009;24(2):190-5.

[PMID:19091448] http://dx.doi.org/10.1016/j.clinbiomech.2008.10.005

47. Koopman BF, Hendriks PJ, Grootenboer HJ. Prosthetic knee stability during the push-off phase of walking-Experimental findings. Engineering in Medicine and Biology Society, 1996. Bridging Disciplines for Biomedicine. Proceedings of the 18th Annual International Conference of the IEEE; 1996 Oct 31-Nov 3; Amsterdam, the Netherlands. p. 471-2. http://dx.doi.org/10.1109/IEMBS.1996.651821

48. Vrieling AH, van Keeken HG, Schoppen T, Hof AL, Otten B, Halbertsma JP, Postema K. Gait adjustments in obstacle crossing, gait initiation and gait termination after a recent lower limb amputation. Clin Rehabil. 2009;23(7):659-71. [PMID:19470553] http://dx.doi.org/10.1177/0269215509102947 
49. Goldberg EJ, Kautz SA, Neptune RR. Can treadmill walking be used to assess propulsion generation? J Biomech. 2008;41(8):1805-8. [PMID:18436229] http://dx.doi.org/10.1016/j.jbiomech.2008.03.009

50. Riley PO, Paolini G, Della Croce U, Paylo KW, Kerrigan DC. A kinematic and kinetic comparison of overground and treadmill walking in healthy subjects. Gait Posture. 2007;26(1):17-24. [PMID:16905322] http://dx.doi.org/10.1016/j.gaitpost.2006.07.003

51. Riley PO, Dicharry J, Franz J, Della Croce U, Wilder RP, Kerrigan DC. A kinematics and kinetic comparison of overground and treadmill running. Med Sci Sports Exerc. 2008;40(6):1093-1100. [PMID:18460996] http://dx.doi.org/10.1249/MSS.0b013e3181677530

52. Warabi T, Kato M, Kiriyama K, Yoshida T, Kobayashi N. Treadmill walking and overground walking of human subjects compared by recording sole-floor reaction force. Neurosci Res. 2005;53(3):343-8. [PMID:16182398] http://dx.doi.org/10.1016/j.neures.2005.08.005

53. Alton F, Baldey L, Caplan S, Morrissey MC. A kinematic comparison of overground and treadmill walking. Clin Biomech (Bristol, Avon). 1998;13(6):434-40. [PMID:11415818] http://dx.doi.org/10.1016/S0268-0033(98)00012-6

54. White SC, Yack HJ, Tucker CA, Lin HY. Comparison of vertical ground reaction forces during overground and treadmill walking. Med Sci Sports Exerc. 1998;30(10): 1537-42. [PMID:9789855] http://dx.doi.org/10.1097/00005768-199810000-00011

55. Selles RW, Bussmann JB, Klip LM, Speet B, Van Soest AJ, Stam HJ. Adaptations to mass perturbations in transtibial amputees: Kinetic or kinematic invariance? Arch Phys Med Rehabil. 2004;85(12):2046-52. [PMID:15605346] http://dx.doi.org/10.1016/j.apmr.2003.10.013

56. Smith JD, Martin PE. Walking patterns change rapidly following asymmetrical lower extremity loading. Hum Mov Sci. 2007;26(3):412-25. [PMID:17289193] http://dx.doi.org/10.1016/j.humov.2006.12.001

57. Noble JW, Prentice SD. Adaptation to unilateral change in lower limb mechanical properties during human walking. Exp Brain Res. 2006;169(4):482-95. [PMID:16328304] http://dx.doi.org/10.1007/s00221-005-0162-3

Submitted for publication December 18, 2014. Accepted in revised form September 29, 2015.

This article and any supplementary material should be cited as follows:

Koehler-McNicholas SR, Lipschutz RD, Gard SA. The biomechanical response of persons with transfemoral amputation to variations in prosthetic knee alignment during level walking. J Rehabil Res Dev. 2016;53(6): 1089-1106.

http://dx.doi.org/10.1682/JRRD.2014.12.0311

ORCID: Sara R. Koehler-McNicholas, PhD: 000-00027201-3607; Steven A. Gard, PhD: 0000-0002-4251-2464

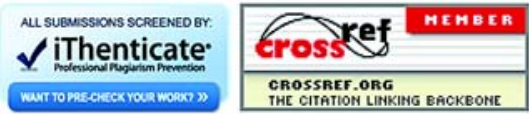

